\title{
中国土壤动物多样性监测: 探知土壤中的奥秘
}

\author{
潘开文 ${ }^{1} \quad$ 张 $^{\text {林 }}{ }^{1}$ 郡元虎 $^{2}$ 傅声雷 $^{2^{*}}$ \\ 1 (中国科学院成都生物研究所, 成都 610041) \\ 2 (中国科学院华南植物园, 广州 510650)
}

\begin{abstract}
摘要: 土壤动物多样性变化及其对环境的指示作用已被学术界和政府决策部门高度关注。本文从土壤动物多样性 监测的重要性及面临的挑战、国内外土壤动物多样性监测概况等方面进行了评述，提出了未来、尤其是2016-2020 年我国土壤动物多样性监测的目标、站点布局、样地设置、监测类群和指标等，并讨论了在制定土壤动物多样性 监测方案时需考虑的问题, 有助于在全国开展多点化土壤动物多样性及分布状况的监测工作, 建立标准统一、数 据共享的土壤动物监测网，提供完整的、可信的监测数据，为国家生态文明建设提供科技支撑。
\end{abstract}

关键词：监测目标；样地设置；监测类群；监测指标；站点布局

\section{Thematic monitoring network of soil fauna diversity in China: exploring the mystery of soils}

\author{
Kaiwen $\mathrm{Pan}^{1}$, Lin Zhang ${ }^{1}$, Yuanhu Shao ${ }^{2}$, Shenglei $\mathrm{Fu}^{2 *}$ \\ 1 Chengdu Institute of Biology, Chinese Academy of Sciences, Chengdu 610041 \\ 2 South China Botanical Garden, Chinese Academy of Sciences, Guangzhou 510650
}

\begin{abstract}
The important roles of soil fauna diversity and associated indicative functions of environment changes have received increasing attention from both academic circles and government decision makers. This paper summarizes the current situation of soil fauna monitoring in developed countries and related work in China. We introduce the objectives and structure of the thematic monitoring network of soil fauna diversity (TMNSFD), and highlighted some aspects that need attention. The TMNSFD proposed to establish permanent monitoring plots within forest plots established by Chinese Forest Biodiversity Monitoring Network for monitoring soil fauna including earthworms, mites, springtails, nematodes and protists. During the years 2016-2020, TMNSFD may choose typical forest ecosystems as priority ecosystems for soil fauna monitoring, which cover temperate forest ecosystems (including broadleaved Korean pine mixed forests in Changbaishan, Jilin Province and warm temperate deciduous broadleaved forests in Donglingshan, Beijing), subtropical forest ecosystems (including typical subtropical evergreen broadleaved forests in Gutianshan, Zhejiang Province, lower subtropical evergreen broadleaved forests in Dinghushan, Guangdong Province, and north subtropical evergreen broad-leaved forests in Dujiangyan, Sichuan Province), tropical forest ecosystems (tropical rainforests in Xishuangbanna, Yunnan Province and Jianfengling, Hainan Province), as well as mountainous dark coniferous forests in Liziping, Sichuan Province. By 2030, TMNSFD soil fauna monitoring plots may cover various ecosystems including forests, grasslands, wetlands, deserts, farmland, urban areas and other typical ecosystems in different regions of China. TMNSFD emphasizes the value of applied molecular biology technology, unified monitoring methods, and manipulation experiments to simulate the effects of global change on soil fauna during the processes of monitoring. We propose monitoring soil fauna diversity once every 5 years in established monitoring plots. The objective of TMNSFD is to provide reliable and integrated data of soil fauna diversity via the establishment of standard monitoring methods and a data-sharing network at the national level, which could support the development of ecological civilization in China.
\end{abstract}

收稿日期: 2016-01-20; 接受日期: 2016-04-19

基金项目：国家自然科学基金(31370632、31500517)和“十三五”国家科技攻关课题(2015BAD07B050304)

* 通讯作者 Author for correspondence. E-mail: sfu@scbg.ac.cn

作者邵元虎和傅声雷现工作单位: 河南大学环境与规划学院, 邮编 475004 
Key words: monitoring objective; plot setting; monitoring group; monitoring index

\section{1 土壤动物多样性监测的重要性及面临的 挑战}

21 世纪以来, 人们开始意识到人类活动引起的 环境污染和全球变化严重威胁着土壤生物多样性 (Turbé et al, 2010; Eisenhauer et al, 2012), 因此对土 壤生物多样性的监测和保护愈加重视(Wall et al, 2001; Gardi et al, 2009; Parker, 2010; 时雷雷和傅声 雷, 2014)。随着工业化和城镇化的快速推进, 我国 生物多样性同样正在经受着前所未有的快速变化, 而这些变化又具有长期性、复杂性、后果滞后性和 难以预测性等特点。对生物多样性动态进行长期的 网络监测研究, 不仅有助于人们认识生物多样性变 化的驱动因子并对其进行量化研究, 而且还有助于 认识生物多样性变化的主导过程及其对生态系统 功能和人类的影响。

陆地生态系统中, 土壤动物是除土壤微生物外 种类最为丰富、数量最多的生物类群。几乎所有的 地下生态学过程都与土壤动物有关, 其在调控生态 系统地上部分的结构、功能和过程中有着至关重要 的作用(Ruiter et al, 1998; Fu et al, 2009)。随着研究 的深入, 研究人员注意到, 土壤动物在表征全球变 化(Wardle et al, 1998; Pritchard, 2011; Li et al, 2012) 和人类活动(Holtkamp et al, 2008, 2011; Susyan et al, 2011)等外来因子对生态系统的扰动方面更具敏感 性, 并能通过营养级联效应对生态系统的地上部分 进行有效反馈, 从而对整个生态系统的构建和维持 有着不可忽视的影响(傅声雷, 2007)。因此, 土壤动 物多样性及其生态功能的研究迅速成为近年来最 受关注的热点之一(Wardle et al, 2004; Fu et al, 2009)。然而, 土壤动物多样性的监测仍然面临相当 大的挑战。首先, 土壤的异质性非常强, 是生物种 类最丰富、数量最多的亚系统, 绝大多数土壤动物 个体很小, 而且土壤动物分类学家和分类手段都十 分缺乏。据估计, 目前仅有 $1-5 \%$ 的土壤动物已被描 述。其次, 土壤生物的习性复杂而且富于变化, 这 对研究土壤生物多样性及其生态功能来说也是巨 大的挑战。土壤动物之间并非简单的取食与被取食 关系，它们之间存在着复杂的正、负反馈过程; 同
时, 土壤食物网的复杂性可能导致土壤生物之间还 存在大量的间接作用, 这些都加大了量化研究的难 度(傅声雷等, 2011)。随着科学界对土壤动物研究的 日益重视, 土壤动物多样性监测与研究迎来了良好 的契机, 突破研究方法和认识上的局限性, 建立长 期的野外监测网络是陆地生态系统和人类社会可 持续发展的迫切要求。

\section{2 国外土壤动物多样性监测的概况}

从 20 世纪 90 年代开始, 拉脱维亚、荷兰、英国、 德国、法国、意大利等国家先后建立了区域和国家 尺度上的土壤动物监测网, 对土壤跳虫、螨类、原 生动物、线虫、蚳蚂等多个土壤动物关键功能群和 群落多样性进行长期监测, 并通过相应数据较好地 表征了土壤生态系统的质量和功能, 为环境科学、 农学、林学以及生态学等相关学科提供了重要的基 础数据。之后在欧盟委员会组织下, 欧洲很多国家 开始合作研究人类干扰和全球变化等对土壤生物 多样性造成的威胁(附录1) (Turbé et al, 2010), 寻找 对威胁因素产生强烈反应的指示类群(Bispo et al, 2009), 制定合理的土壤生物多样性监测和保护体 系(Gardi et al, 2009)。其中做得最好的是荷兰和英 国, 但需要指出的是完成一次全面的土壤动物监测 的周期很长, 荷兰 6 年才完成一个采样周期, 而英 国仅在1998年和2007年进行了比较系统的采样 (Turbé et al, 2010)。总之, 欧盟委员会在土壤生物多 样性的监测、评价、保护与立法方面都采取了具体 而有代表性的行动。2010年, 欧盟委员会下属的环 境研究所和联合研究中心分别完成了 Soil Biodiversity: Functions, Threats and Tools for Policy Makers 和European Atlas of Soil Biodiversity 两本报告, 系 统总结了现阶段人们对土壤生物多样性的认识和 土壤生物多样性面临的一些威胁(Turbé et al, 2010; Jeffery et al, 2010; 时雷雷和傅声雷, 2014)。2011年 底, 著名土壤生态学家Diana H. Wall, Wim van der Putten, Richard D. Bardgett, Johan Six 和Luca Montanarella共同建立全球土壤生物多样性研究的交流 平台(Global Soil Biodiversity Initiative, http://www. globalsoilbiodiversity.org/), 旨在号召各国加强对土 
壤生物多样性的积极研究, 并将获得的知识应用于 环境政策和可持续管理(时雷雷和傅声雷, 2014)。尽 管上述国家已在监测方面做了很多工作, 但是受地 域限制, 很难在大尺度上开展监测工作, 即使可以 整合获得的监测数据, 但难以保证这些数据在采样 时间上的一致性。另外, 这些国家有的倾向于监测 大型土壤动物, 有的倾向于监测中型或小型土壤动 物, 同步监测大中小型土壤动物的国家只有英国和 荷兰, 这对大尺度上整合研究土壤动物间的相互作 用来说是很大的局限。号召不同国家之间的合作并 整合这些国家的监测数据, 仍然是发达国家在监测 方面的一个发展趋势。

\section{3 我国土壤动物多样性研究和监测的概况}

近 20 年来, 土壤动物多样性研究在我国发展较 快。其中, 中国科学院是我国最早全面开展土壤动 物多样性及其相关研究的单位。20世纪 90 年代, 中 国科学院上海植物生理生态研究所尹文英院士组 织编撰的《中国土壤动物检索图鉴》, 奠定了我国 深入开展土壤动物研究的基础。进入 21 世纪后, 以 中国科学院华南植物园、沈阳应用生态研究所、东 北地理与农业生态研究所、西双版纳热带植物园等 为代表的研究所在我国不同区域开展了大量工作, 获取了丰富的基础数据资料, 取得了一系列突出的 成果(Shao et al, 2008; Sun \& Wu, 2012; Yang et al, 2012; Chang et al, 2013)。但这些研究工作主要集中 在华南和东北等区域, 中西部广大腹地土壤动物的 研究基础相对薄弱; 部分生态功能重要区域和地上 生物多样性热点区域(如横断山区、青藏高原等)的 土壤动物研究工作则起步较晚(李玲娟等, 2015)。各 区域研究不平衡的现状导致土壤动物监测研究难 以全面开展, 数据局限性较强, 因而急需建立覆盖 全国重点区域的标准统一、数据共享的土壤动物监 测网, 为社会提供完整的、可信的监测数据。此外, 从已有的研究来看, 土壤动物个体小、生命周期短 而且绝大多数种类对环境十分敏感, 温度、水分、 土壤营养状况等因素都能很大程度上影响其种群 的变化。尤其是地上植被组成与土壤动物分布特征 (种类和数量)有着非常紧密的联系, 土壤动物群落 结构和功能对地上植被类型变化也有着很好的反 馈作用。我国地域辽阔, 拥有多个气候类型, 形成 多种植被地理分布格局, 孕育了丰富的土壤动物,
对于大尺度上开展土壤动物的监测工作来说具有 得天独厚的条件。但迄今为止，我国开展的生物多 样性监测工作主要集中在地上部分，而针对土壤动 物多样性开展的监测工作则十分缺乏。因此, 有必 要在我国典型区域选择有代表性的生态系统开展 土壤动物的监测工作。

\section{4 我国土壤动物多样性监测的目标}

为进一步丰富国家尺度下土壤动物的基础资 料, 回答全球气候变化和人类活动对地下生物多样 性影响等热点科学问题及国家战略需求, 中国科学 院拟建立土壤动物多样性监测专项网, 作为中国生 物多样性监测网络的有机组成部分(马克平，2015), 在全国开展多点化土壤动物多样性及分布状况的 监测工作，从而揭示土壤动物多样性的空间分布、 时间变化规律及其对外来干扰的反馈效应和对地 下生态过程的调控机理。具体目标如下：(1)开展土 壤动物多样性监测，整合各监测点数据，建立“全 国土壤动物数据库”, 从而为国家生物多样性保护 和生物资源储备提供基础数据, 为工程实施和政策 制定提供科学依据，促进多学科的协同发展; (2)揭 示土壤动物多样性的分布规律及其变化的驱动机 制，阐明土壤动物多样性对全球变化和人类活动的 响应机制, 识别其受胁迫因素, 为土壤动物多样性 保护和资源合理利用、土壤肥力和生态系统生产力 的维持提供科学支撑; (3)整合政策和科学方面的需 求, 对土壤动物多样性保护和管理提出建议和规 划，形成有效调控手段，促进资源可持续利用、土 壤肥力提升和生态系统生产力的维持。

\section{5 我国土壤动物多样性监测点布局}

考虑到土壤动物巨大的多样性和数量以及专 业人员的缺乏, 在专项网建设的具体操作和实施 上，拟选择我国典型区域的代表性植被类型，依托 已建成的生物多样性监测大样地、野外台站和实验 基地, 先期进行监测点布局, 重点以中国科学院生 物多样性委员会组织建设的中国森林生物多样性 监测网络(CForBio, www.cfbiodiv.org/)大型森林固 定样地为对象, 开展土壤动物多样性监测 (2016-2020年), 初步形成森林生态系统土壤动物监 测网体系; 到2030年, 最大可能地涵盖我国不同区 域的森林、草原、湿地、荒漠、农田和城市等各类 
典型生态系统。在第一期规划(2016-2020年)中, 土 壤动物专项网拟初步设置主监测点 8 个, 由北至南 分别分布在吉林、北京、浙江、广东、四川、云南 和海南, 分别代表不同气候区域的典型森林生态系 统, 条件成熟时再适当增设一些辅助监测点并选择 其他类型的生态系统布设监测点。其中, 位于吉林 长白山的温带红松落叶阔叶混交林生态系统由中 国科学院沈阳应用生态所和东北地理与农业生态 所监测, 位于北京东灵山的暖温带落叶阔叶林生态 系统由中国科学院动物所和东北地理与农业生态 所监测, 位于浙江古田山的亚热带常绿阔叶林生态 系统由中国科学院上海生命科学研究院植物生理 生态研究所监测, 位于广东鼎湖山的南亚热带常绿 阔叶林生态系统由中国科学院华南植物园监测, 位 于四川都江堰的亚热带常绿阔叶林生态系统由中 国科学院成都生物所和成都山地灾害与环境所监 测, 位于四川栗子坪亚热带区域的山地暗针叶林生 态系统由中国科学院成都生物所和成都山地灾害与 环境所监测, 位于云南西双版纳的热带雨林生态系 统由中国科学院西双版纳热带植物园监测, 位于海 南尖峰岭的热带雨林生态系统由中国科学院华南植 物园、中国林业科学研究院热带林业研究所监测。

\section{6 我国土壤动物多样性监测样地设置}

在大型森林固定样地内, 拟选择典型的地带性 植被设置 3 个 $20 \mathrm{~m} \times 20 \mathrm{~m}$ 的样方, 每个样方选取 5 个 $5 \mathrm{~m} \times 5 \mathrm{~m}$ 的采样区, 分别以样方四角和样方中心点 为采样区。类似的, 在每个采样区内的四角和中心 选取 5 个采样点, 这 5 个采样点的土壤可以混合成 1 个混合样。这样每个大样地的典型地带性植被每次 采样数量为 15 个 ( 3 个样方 $\times 5$ 个混合样)。每次监测 网合计采样 120 个 $(8$ 个大样地 $\times 15$ 个混合样)。事实 上, 每个大样地内地形比较复杂, 以鼎湖山大样地 为例, 大样地内的植被类型沿海拔梯度依次分布有 沟谷雨林、南亚热带常绿阔叶林、山地常绿阔叶林 或山地常绿灌从和山地常绿灌草从。除大样地内的 典型地带性植被作为监测网设置的主要采样点外, 其他植被类型可以根据需要采样。

\section{7 我国土壤动物多样性监测的主要类群和 指标}

专项网监测工作以土壤食物网构成的不同土
壤动物类群作为监测对象。其中, 大型土壤动物主 要包括肉眼可见的大型无脊椎动物(例如土壤昆虫 和虹蚓等), 以监测蚟蚓为主; 中型土壤动物主要包 括螨类、跳虫等; 小型土壤动物主要包括线虫等。 然而不同土壤动物类群的大小及形态差别很大, 比 如大型土壤动物中的蚯蚓, 比较容易获得多度、生 物量和多样性等指标, 可直接作为监测指标。中型 动物中的跳虫鉴定相对螨虫简单一些, 可通过评估 其多度和多样性来反映生态系统的健康状况。而螨 虫数量庞大, 类群众多, 可优先得到多度、生物量 及几个主要的功能群的信息, 在条件允许的情况下 进行细分以获得更加详细的信息。线虫的个体较小, 其多度相对容易获得, 但准确测定生物量则相对困 难, 可根据不同类群的生活史特性和相对多度计算 成熟指数(Bongers，1990)、富集指数及结构指数等 (Ferris et al, 2001)。随着监测工作的不断深入, 这些 分类群的监测指标还可进一步整合, 分析食物网的 稳定性及复杂性, 预测土壤生态系统对扰动的抵抗 力以及在受到扰动之后的恢复力。在各监测点, 采 用定点、长期监测(辅以土壤动物群落调查等)的统 一方法, 通过监测土壤动物群落的个体数、密度、 频度、生物量、食性、性别比等特征指标, 以及植 被类型、优势植物种、海拔、湿度、光照、土壤理 化性质等, 实现对土壤动物的物种、食性和功能群、 食物网结构和生存环境等本底数据进行长期监测 和记录的目的。在此基础上, 对所搜集到的数据进 行整理、信息化, 建立土壤动物数据库。

\section{8 土壤动物多样性监测方案制定需考虑的 问题}

关于监测方案的制定方面, 有以下几点需要强 调:

(1)越来越多的证据表明, 全球气候变化对土壤 生物多样性及其生态功能具有重要影响。因此, 结 合全球变化的背景设置一些有针对性的监测样地 (比如温度或水分梯度) 是有必要的。同时, 如果能设 置一些相应的控制实验以模拟全球变化因子对土 壤动物多样性的影响, 并结合野外监测平台的实验 结果, 可能会对未来模型模拟研究起到一定的推动 作用。

(2) 土壤动物种类繁多、数量庞大, 而土壤动物 传统的形态学鉴定工作量大、专业人才缺乏。目前, 
在土壤动物研究方面已开始了分子技术鉴定研究 的尝试性工作。比如, 欧洲土壤动物监测的前 10 位 类群中, 有7个使用了分子方法(Stone et al, 2016)。 土壤动物形态鉴定非常耗时, 且很多幼虫难以鉴 定, 如果将常规形态鉴定与分子技术相结合或许会 对开展大规模的采样和土壤动物多样性分析起到 很大的推动作用(邵元虎等, 2015)。

(3)根据欧盟发达国家的监测经验(Turbé et al, 2010), 3-5年进行一次集中采样可能是相对比较可 行的。

(4)土壤动物常常是土壤生态系统服务的驱动 者, 而不同研究者采用的采样方法、研究方法以及 实验手段都或多或少有一定的差别, 在监测网框架 下选择统一的监测方法收集数据很有必要。此外, 这些数据标准化后再整合分析同样重要, 特别是在 食物网水平上分析土壤动物多样性和生态系统功 能之间的关系会加深我们对土壤动物多样性和土 壤质量及其功能之间关系的理解, 也有利于建立研 究者和政策制定者之间的桥梁。

最后，希望专项网的执行能帮助我们实现以下 目标: (1)基本掌握土壤动物的分布格局及其变化规 律; (2)了解土壤动物多样性面临的威胁及其原因; (3)形成一套相对统一的监测方法; (4)结合生态学的 知识和新的方法, 把土壤动物多样性研究结果与生 态系统功能与服务结合并应用于政策和教育, 为国 家生态文明建设和可持续发展提供科技支撑。

\section{参考文献}

Bispo A, Cluzeau D, Creamer R, Dombos M, Graefe U, Krogh PH, Sousa JP, Peres G, Rutgers M, Winding A (2009) Indicators for monitoring soil biodiversity. Integrated Environmental Assessment and Management, 5, 717-719.

Bongers T (1990) The maturity index: an ecological measure of environmental disturbance based on nematode species composition. Oecologia, 83, 14-19.

Chang L, Wu HT, Wu DH, Sun X (2013) Effect of tillage and farming management on Collembola in marsh soils. Applied Soil Ecology, 64, 112-117.

Eisenhauer N, Cesarz S, Koller R, Worm K, Reich PB (2012) Global change belowground: impacts of elevated $\mathrm{CO}_{2}$, nitrogen, and summer drought on soil food webs and biodiversity. Global Change Biology, 18, 435-447.

Ferris H, Bongers T, de Goede RGM (2001) A framework for soil food web diagnostics: extension of the nematode faunal analysis concept. Applied Soil Ecology, 18, 13-29.

Fu SL, Zhang WX, Shao YH, Xu GL (2011) 10000 Scientific Problem (Agricultural volume). Science Press, Beijing. (in
Chinese) [傅声雷, 张卫信, 邵元虎, 徐国良 (2011) 10000 个科学难题(农学卷). 科学出版社, 北京.]

Fu SL (2007) A review and perspective on soil biodiversity research. Biodiversity Science, 15, 109-115. (in Chinese with English abstract) [傅声雷 (2007) 土壤生物多样性的 研究概况与发展趋势. 生物多样性, 15, 109-115.]

Fu SL, Zou XM, Coleman D (2009) Highlights and perspectives of soil biology and ecology research in China. Soil Biology and Biochemistry, 41, 868-876.

Gardi C, Montanarella L, Arrouays D, Bispo A, Lemanceau P, Jolivet C, Mulder C, Ranjard L, Römbke J, Rutgers M (2009) Soil biodiversity monitoring in Europe: ongoing activities and challenges. European Journal of Soil Science, $60,807-819$.

Holtkamp R, van der Wal A, Kardol P, van der Putten WH, de Ruiter PC, Dekker SC (2011) Modeling C and N mineralisation in soil food webs during secondary succession on ex-arable land. Soil Biology and Biochemistry, 43, 251-260.

Holtkamp R, Kardol P, van der Wal A, Dekker SC, van der Putten WH, de Ruiter PC (2008) Soil food web structure during ecosystem development after land abandonment. Applied Soil Ecology, 39, 23-34.

Jeffery S, Gardi C, Jones A, Montanarella L, Marmo L, Miko L, Ritz K, Peres G, Römbke J, Putten W (2010) European Atlas of Soil Biodiversity. European Commission, Luxembourg.

Li LJ, Xiong QL, Pan KW, Zhang L (2015) The responses of soil protozoan communities to Quercus aquifolioides: recovery after cutting and growing season dynamics. Biodiversity Science, 23, 793-801. (in Chinese with English abstract) [李玲娟, 熊勤犁, 潘开文, 张林 (2015) 土壤原生 动物对川滇高山栎恢复时间的响应及生长季动态. 生物 多样性, 23, 793-801.]

Li Q, Bao XL, Lu CY, Zhang XK, Zhu JG, Jiang Y, Liang WJ (2012) Soil microbial food web responses to free-air ozone enrichment can depend on the ozone-tolerance of wheat cultivars. Soil Biology and Biochemistry, 47, 27-35.

Ma KP (2015) Biodiversity monitoring in China: from CForBio to Sino BON. Biodiversity Science, 23, 1-2. (in Chinese) [马克平 (2015) 中国多样性监测网络建设: 从CForBio到 Sino BON. 生物多样性, 23, 1-2.]

Parker SS (2010) Buried treasure: soil biodiversity and conservation. Biodiversity and Conservation, 19, 3743-3756.

Pritchard SG (2011) Soil organisms and global climate change. Plant Pathology, 60, 82-99.

Ruiter PCD, Neutel AM, Moore JC (1998) Biodiversity in soil ecosystems: the role of energy flow and community stability. Applied Soil Ecology, 10, 217-228.

Shao YH, Zhang WX, Liu SJ, Wang XL, Fu SL (2015) Diversity and function of soil fauna. Acta Ecologica Sinica, 35, 6614-6625. [邵元虎, 张卫信, 刘胜杰, 王晓丽, 傅声雷 (2015) 土壤动物多样性及其生态功能. 生态学报, 35 , 6614-6625.]

Shao YH, Zhang WX, Shen JC, Zhou LX, Xia HP, Shu WS, 
Ferris H, Fu SL (2008) Nematodes as indicators of soil recovery in tailings of a lead/zinc mine. Soil Biology and Biochemistry, 40, 2040-2046.

Shi LL, Fu SL (2014) Review of soil biodiversity research: history, current status and future challenges. Chinese Science Bulletin, 59, 493-509. (in Chinese with English abstract) [时雷雷, 傅声雷 (2014) 土壤生物多样性研究: 历 史、现状与挑战. 科学通报, 59, 493-509.]

Stone D, Ritz K, Griffiths BG, Orgiazzi A, Creamer RE (2016) Selection of biological indicators appropriate for European soil monitoring. Applied Soil Ecology, 97, 12-22.

Sun X, Wu DH (2012) Two new species of the genus Sensillonychiurus Pomorski et Sveenkova, 2006 (Collembola: Onychiuridae) from Changbai Mountains, China. Annales Zoologici, 62, 563-570.

Susyan EA, Wirth S, Ananyeva ND, Stolnikova EV (2011) Forest succession on abandoned arable soils in European Russia-Impacts on microbial biomass, fungal-bacterial ratio, and basal $\mathrm{CO}_{2}$ respiration activity. European Journal of Soil Biology, 47, 169-174.

Turbé A, Toni A De, Benito P, Lavelle P, Lavelle P, Ruiz N, van der Putten WH, Labouze E, Mudgal S (2010) Soil biodiversity: functions, threats and tools for policy makers. Bio Intelligence Service, IRD, and NIOO, Report for European Commission (DG Environment).

Wall DH, Snelgrove PVR, Covich A (2001) Conservation priorities for soil and sediment invertebrates. In: Conservation Biology: Research Priorities for the Next Decade (eds Soule ME, Orians GH), pp. 99-123. Island Press, Washington.

Wardle DA, Bardgett RD, Klironomos JN, Setälä H, van der Putten WH, Wall DH (2004) Ecological linkages between aboveground and belowground biota. Science, 304, 1629-1633.

Wardle DA, Verhoef HA, Clarholm M (1998) Trophic relationships in the soil micro food-web: predicting the responses to a changing global environment. Global Change Biology, 4, 713-727.

Yang XD, Yang Z, Warren MW, Chen J (2012) Mechanical fragmentation enhances the contribution of Collembola to leaf litter decomposition. European Journal of Soil Biology, $53,23-31$.

\section{附录 Supplementary Material}

附录1 部分欧洲国家对土壤生物的监测(引自Turbé et al, 2010)

Appendix 1 Monitoring soil animal in Europe (from Turbé et al, 2010)

http://www.biodiversity-science.net/fileup/PDF/2016019-1.pdf 
潘开文, 张林, 邵元虎, 傅声雷. 中国土壤动物多样性监测: 探知土壤中的奥秘. 生物多样性, 2016, 24 (11): $1234-1239$.

http://www.biodiversity-science.net/CN/10.17520/biods.2016019

附录1 部分欧洲国家对土壤生物的监测(引自 Turbé et al, 2010)

Appendix 1 Monitoring soil animal in Europe (from Turbé et al, 2010)

\begin{tabular}{|c|c|c|c|c|c|c|}
\hline \multirow{4}{*}{$\begin{array}{l}\text { 国家 } \\
\text { Country }\end{array}$} & \multicolumn{4}{|c|}{ 监测指标 } & \multirow{4}{*}{$\begin{array}{c}\text { 采样频率 } \\
\text { Frequency of } \\
\text { sampling }\end{array}$} & \multirow{4}{*}{$\begin{array}{l}\text { 尺度 } \\
\text { Scale }\end{array}$} \\
\hline & \multicolumn{4}{|c|}{ Organisms monitored } & & \\
\hline & 蚳蚓 & 跳虫 & 螨类 & 线虫 & & \\
\hline & Earthworm & Collembola & Mite & Nematode & & \\
\hline 奥地利 & + & + & - & - & 不确定 & 区域尺度 \\
\hline Austria & & & & & Uncertain & Regional \\
\hline 捷克 & - & - & - & - & 每年1次 & 国家尺度仅对微生物指标监测 \\
\hline Czech & & & & & Annual & National (microbiological parameters) \\
\hline $\begin{array}{l}\text { Republic } \\
\text { 汢国 }\end{array}$ & + & 0 & 0 & - & 区域尸度上每年妥样1次国家尸度 & 区域民度上临测微生物 十刑十培动物 \\
\hline France & & & & & 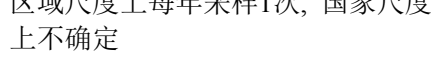 & 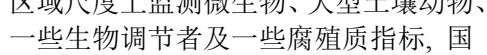 \\
\hline & & & & & $\begin{array}{l}\text { Annual for regional scale, not yet } \\
\text { decided for national scale }\end{array}$ & $\begin{array}{l}\text { 家尺度上监测细菌和真菌多样性 } \\
\text { Microbes (biomass, bacterial and fungal } \\
\text { diversity, soil respiration), biological } \\
\text { regulators, macrofauna (earthworms, total } \\
\text { macro-fauna), humus index at regional } \\
\text { scale; Microbes (bacterial and fungal } \\
\text { diversity) at national scale }\end{array}$ \\
\hline 德国 & 0 & 0 & 0 & 0 & 不确定 & 区域尺度 ～～～～～～～～～～ \\
\hline Germany & & & & & Uncertain & Regional \\
\hline 意大利 & - & + & + & - & 不确定 & 区域尺度上监测小型节肢动物 \\
\hline Italy & & & & & Uncertain & Regional \\
\hline 拉脱维亚 & 0 & + & + & - & 每年1次 & 国家尺度上监测中型和表栖类土壤动物 \\
\hline Latvia & & & & & Annual & $\begin{array}{l}\text { Meso-fauna and epigeic fauna at national } \\
\text { scale }\end{array}$ \\
\hline 荷兰 & + & + & + & + & 十类土每年采两类, 6年完成1次监 & 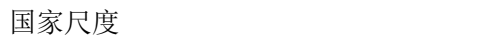 \\
\hline Netherlands & & & & & $\begin{array}{l}\text { 测网络的全部采样 } \\
\text { Two soil/landuse types sampled an- } \\
\text { nually, so one cycle to cover whole } \\
\text { network takes } 6 \text { years }\end{array}$ & National \\
\hline 罗马尼亚 & - & - & - & - & 4年1次, 个别点每年1次 & 国家尺度上监测细菌和真菌 \\
\hline Romania & & & & & $\begin{array}{l}\text { Every four years, unless site is par- } \\
\text { ticularly degraded in which case } \\
\text { monitoring is annual }\end{array}$ & $\begin{array}{l}\text { Bacteria and fungi (number) at national } \\
\text { scale }\end{array}$ \\
\hline 英国 & + & + & + & + & 1998年和2007年 & 国家尺度上监测无脊椎动物 \\
\hline $\begin{array}{l}\text { United } \\
\text { Kingdom }\end{array}$ & & & & & $\begin{array}{l}\text { Since biological measurements were } \\
\text { added, surveys have been done in } \\
1998 \text { and } 2007\end{array}$ & Invertebrates at national scale \\
\hline
\end{tabular}

“+”表示已监测, “-”表示未监测, “0”表示不确定。

“+” means monitored, “-” means no monitoring, “ 0 ” indicates uncertainty. 